\title{
Structural and Electrical Studies on Zinc Added Magnesium Oxide Nanoparticles
}

\author{
Sumithraj Premkumar P. \\ Department of Physics, St. John's College, Palayamkottai, Tirunelveli 627002, \\ Tamilnadu, India \\ E-mail: psumithraj@gmail.com
}

Published online: 25 November 2020

To cite this article: Sumithraj Premkumar, P. (2020). Structural and electrical studies on zinc added magnesium oxide nanoparticles. J. Phys. Sci., 31(3), 73-86. https://doi .org/10.21315/jps2020.31.3.6

To link to this article: https://doi.org/10.21315/jps2020.31.3.6

\begin{abstract}
Magnesium oxide ( $\mathrm{MgO}$, pure) and zinc added $\mathrm{MgO}$ nanoparticles were synthesised by a simple microwave assisted solvothermal method. The concentrations of impurity used in the present work were $0.25 \mathrm{M}$ and $0.50 \mathrm{M}$. All samples were annealed at $400^{\circ} \mathrm{C}$ for $1 \mathrm{~h}$ to improve the ordering. The prepared pure and zinc added magnesium oxide nanoparticles were characterised by powder X-ray diffraction (PXRD), energy dispersive spectroscopy (EDS) and scanning electron microscopy (SEM). PXRD studies of pure and zinc added $\mathrm{MgO}$ nanoparticles showed that all samples belong to crystalline nature with cubic structure. The grain size of all samples were determined from the XRD results and it belongs to nanometre scale. The EDS confirmed the presence of zinc, magnesium and oxide elements in the respective prepared samples. The scanning electron microscope images confirmed that the prepared samples possess nanometer dimensions. The electrical properties such as AC conductivity, dielectric constant and dielectric loss were measured at different temperatures in the different frequency range by involving the impedance analyser of all the prepared samples.
\end{abstract}

Keywords: Magnesium oxide nanoparticles, XRD, EDS, SEM, electrical properties

\section{INTRODUCTION}

Metal oxides such as magnesium oxide $(\mathrm{MgO})$, iron oxide $(\mathrm{FeO})$ and copper oxide $(\mathrm{CuO})$ are inorganic compound and most of them exhibit a rock salt structure. These oxides are widely used as an additive in numerous materials and products such as rubbers, plastics, ceramics, glass, cement, lubricants, paints, ointments, adhesives, sealants, pigments, foods, batteries, ferrites, fire retardants and first-aid 
tapes. ${ }^{1}$ Mixed metal oxides have found increasing research focus and applications in physics, chemistry, materials science and engineering. The combination of two or more metals in an oxide matrix can produce materials with novel physical and chemical properties leading to relatively higher performance in various technological applications.

Zinc oxide $(\mathrm{ZnO})$ and $\mathrm{MgO}$ are wide band gap semiconductors with an energy gap of $3.37 \mathrm{eV}$ and $7.82 \mathrm{eV}$ at room temperature, respectively. ${ }^{2}$ They possess unique optical, electronic, magnetic, thermal, mechanical and chemical properties due to its characteristic structures. ${ }^{3,4}$ Recently, the interest in $\mathrm{ZnO}$ has grown due to its potential use in numerous technological applications such as transparent conducting electrodes, display materials, light emitting diodes (LEDs), gas sensors, solar cells, laser systems, etc. ${ }^{5-7} \mathrm{MgO}$ attracts attention owing to its interesting properties in bulk as well as in the form of nanoparticles. Nanoscale $\mathrm{MgO}$ is of interest because at this scale, unique structural, optical, electrical and other properties emerge. These emergent properties have the potential for impacts in electronics, mechanical fields and it is expected that the addition of zinc into the $\mathrm{MgO}$ nanoparticles will lead to a great impact on the engineering fields.

Several research reports are available on $\mathrm{ZnO}$ and $\mathrm{MgO}$ nanoparticles. ${ }^{8-18}$ In the present study, pure and zinc added $\mathrm{MgO}$ nanoparticles were prepared by a simple solvothermal method using a domestic microwave oven. The prepared samples were characterised by making powder X-ray diffraction (PXRD), scanning electron microscope (SEM) and energy dispersive spectroscopy (EDS). The electrical parameter measurements such as AC electrical conductivity, dielectric constant and loss were also done.

\section{EXPERIMENTAL}

\subsection{Materials}

Analytical reagent grade zinc acetate, magnesium acetate, urea and ethylene glycol were used for the preparation of zinc added $\mathrm{MgO}$ nanoparticles. These precursors were purchased from Merck, Germany.

\subsection{Methods}

The homogeneous mixture of magnesium acetate, urea in 1:3 molecular ratio with ethylene glycol was prepared and kept in a microwave oven $(2.45 \mathrm{kHz}, 15 \mathrm{~min})$ for microwave irradiation. The colloidal precipitate obtained was cooled and washed with deionised water and acetone to remove the impurities present, if any. 
Then the washed samples were dried in atmospheric air and collected as the pure $\mathrm{MgO}$ nanoparticles. The schematic representation of the $\mathrm{MgO}$ nanoparticle is presented in Figure 1. An amount of $0.25 \mathrm{M}$ and $0.5 \mathrm{M}$ analytical grade zinc acetate was added to a mixture of magnesium acetate, urea and ethylene glycol for the preparation of zinc added $\mathrm{MgO}$. Then the process such as irradiation and washing were repeated for the preparation of zinc added $\mathrm{MgO}$ nanoparticles. Finally, the pure and zinc added $\mathrm{MgO}$ nanoparticles were collected and annealed at $400^{\circ} \mathrm{C}$ for $1 \mathrm{~h}$.

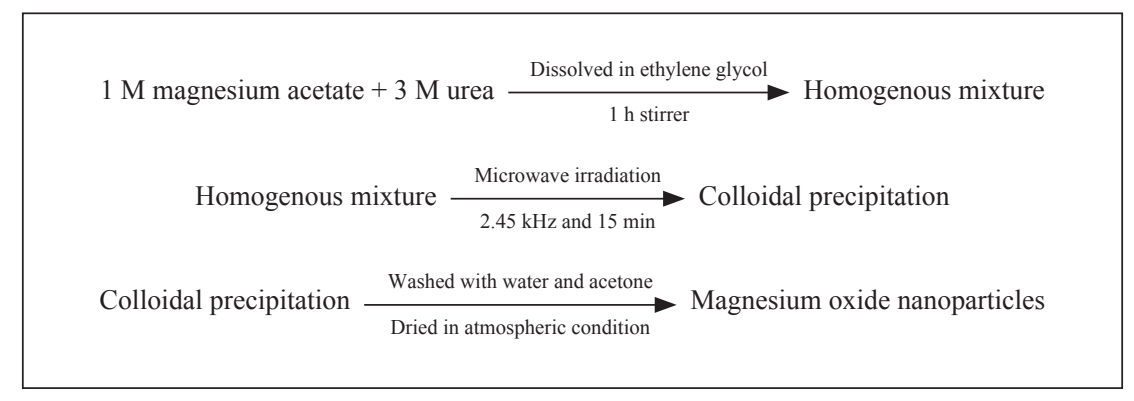

Figure 1: Schematic representation of the $\mathrm{MgO}$ nanoparticle.

\subsection{Characterisation}

In order to get exact information about the crystal structure, surface morphology and particle size, the prepared samples were characterised by PXRD (Panalytical make, model X'per PRO/Netherlands), EDS (Broker/Germany) and SEM (JSM6390/Germany). The electrical parameters such as AC electrical conductivity, dielectric constant and dielectric loss of all the prepared samples were measured by the result obtained from the impedance analyser (Zahner-IM6/Germany) at different temperatures in the frequency range of $1 \mathrm{~Hz}-100 \mathrm{kHz}$.

\section{RESULTS AND DISCUSSION}

\subsection{Structural Studies}

The diffraction patterns of pure, $0.25 \mathrm{M}$ and $0.05 \mathrm{M}$ zinc added $\mathrm{MgO}$ nanoparticles were obtained using $\mathrm{CuK}_{\alpha}$ radiation at wavelength $1.5406 \AA$. The obtained PXRD pattern of pure MgO was indexed and compared with JCPDS data (file no. 45-0946). Figure 2 shows the indexed PXRD patterns of the pure, $0.25 \mathrm{M}$ and $0.5 \mathrm{M}$ zinc added $\mathrm{MgO}$ nanoparticles. The synthesised nanoparticles have crystalline nature and they are in the cubic form as all the peaks are prominent. 

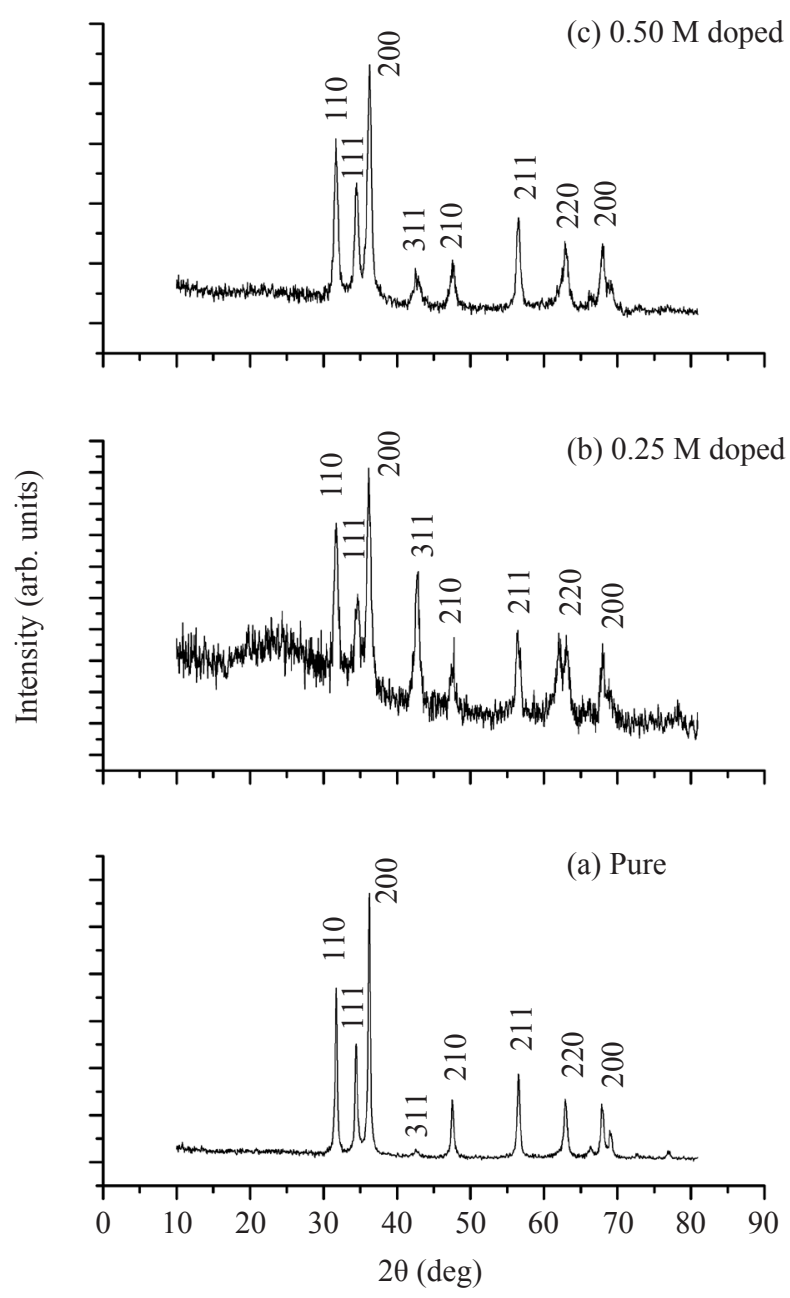

Figure 2: Indexed PXRD pattern of pure and zinc added $\mathrm{MgO}$ nanoparticles.

The PXRD pattern showed that the variation of intensity was observed in the zinc added $\mathrm{MgO}$ nanoparticle compared to the pure $\mathrm{MgO}$ nanoparticles which confirm the entry of zinc into the $\mathrm{MgO}$ crystal lattice. The lattice parameters of pure, $0.25 \mathrm{M}$ and $0.5 \mathrm{M}$ zinc added $\mathrm{MgO}$ nanoparticles were determined by considering high reflections from the PXRD pattern using the method adopted in the literature. ${ }^{19,20}$ The average grain size has been estimated using the Debye-Scherrer formula. The calculated lattice volume and grain size of pure and zinc added $\mathrm{MgO}$ nanoparticles are presented in Table 1. 
Table 1: Lattice parameters of pure and $\mathrm{Zn}$ added $\mathrm{MgO}$ nanoparticles.

\begin{tabular}{lcc}
\hline Sample & Lattice volume $\left(\AA^{3}\right)$ & Grain size $(\mathrm{nm})$ \\
\hline Pure $\mathrm{MgO}$ & 74.6929 & 17.54 \\
$0.25 \mathrm{M}$ zinc added $\mathrm{MgO}$ & 74.6984 & 19.82 \\
$0.50 \mathrm{M}$ zinc added $\mathrm{MgO}$ & 74.7018 & 22.59 \\
\hline
\end{tabular}

From Table 1, it can be understood that the addition of zinc doping had almost no effect on the $\mathrm{MgO}$ crystalline structure, indicating that zinc ions homogeneously mixed and effectively doped in the host lattice in magnesium sites. However, it was observed that the mean grain size was found to increase with an increase in zinc molar concentration. This indicates that the zinc doped on the host matrix was strongly capped into the crystal lattice and caused contraction of the unit cell because the ionic radii of zinc are higher than that of magnesium.

The EDS of pure, $0.25 \mathrm{M}$ and $0.50 \mathrm{M}$ zinc added $\mathrm{MgO}$ nanoparticles were carried out to identify the elements present in the prepared samples. The EDS spectra of these nanoparticles are shown in Figure 3.

In Figure 3, it is understood that the presence of magnesium, zinc and oxygen elements have identified from the respective energy value of $1.253 \mathrm{keV}$, $8.630 \mathrm{keV}$ and $0.525 \mathrm{keV}$. There is no identification (evidence) of the zinc element in the pure $\mathrm{MgO}$ nanoparticles. But in the case of $0.25 \mathrm{M}$ and $0.50 \mathrm{M}$ zinc added $\mathrm{MgO}$ nanoparticles, characteristic peaks were observed in the respective energy. The observed percentage of all elements in prepared nanoparticles is in good agreement with the experimental value. From these results, it may be concluded that the prepared samples are pure, $0.25 \mathrm{M}$ and $0.50 \mathrm{M}$ zinc added $\mathrm{MgO}$ nanoparticles. 

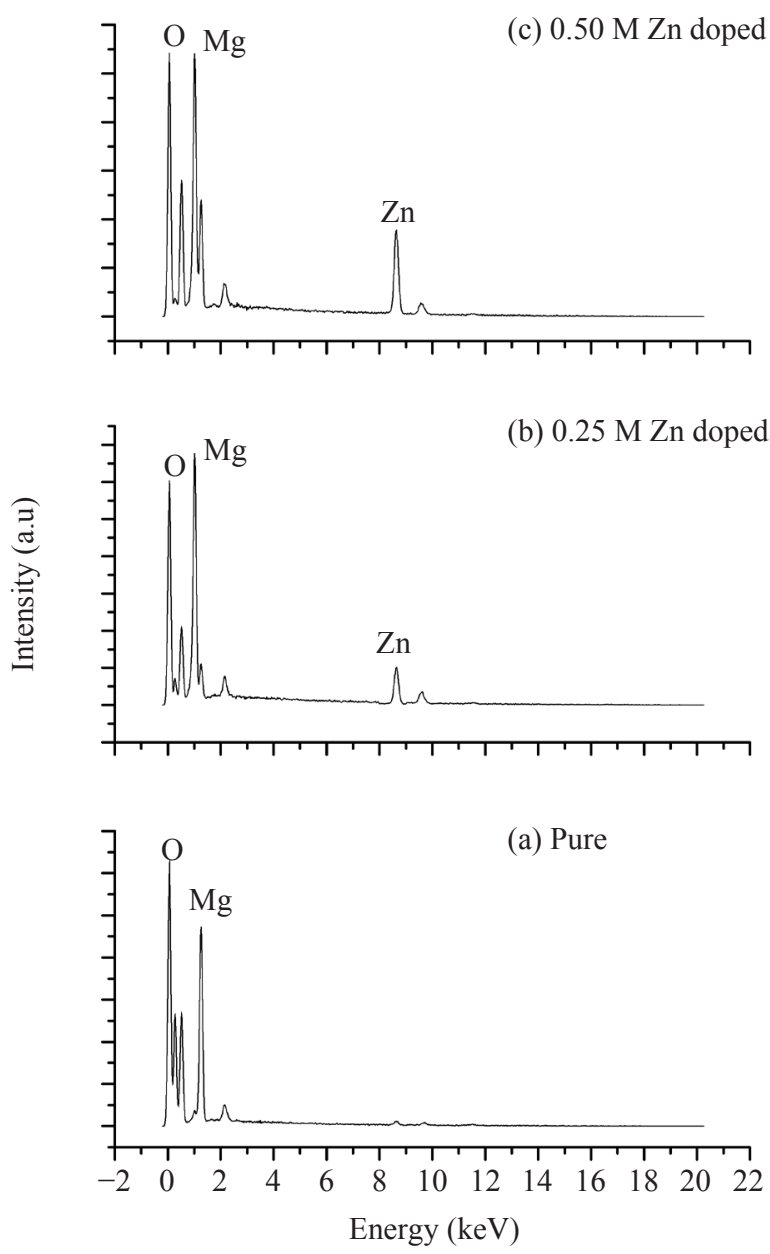

Figure 3: EDS of pure and zinc added $\mathrm{MgO}$ nanoparticles.

The morphology and topography of the samples were investigated using the imaging technique of SEM. The SEM images of isolated pure, $0.25 \mathrm{M}$ and $0.50 \mathrm{M}$ zinc added $\mathrm{MgO}$ nanoparticles are shown in Figure 4.

The SEM images clearly indicate the formation of nanoclusters. The prepared pure and zinc added $\mathrm{MgO}$ nanoparticles are predominantly spherical, uniform and monodispersed which showed that the oxide nanoparticles had the tendency to form spherical agglomeration. The rough and spongy surface morphology of pure, 0.25 $\mathrm{M}$ and $0.50 \mathrm{M}$ zinc added $\mathrm{MgO}$ nanoparticles are evident which makes it difficult to estimate the crystallite size due to agglomeration of the particles. SEM also shows that the doping process is often accompanied by changes in morphology. 
From the image of pure, $0.25 \mathrm{M}$ and $0.50 \mathrm{M}$ zinc added $\mathrm{MgO}$ nanoparticles, the shape of the nanoparticles is quasi-spherical but the actual size of the nanoparticles cannot be distinguished from the SEM image merely, because SEM shows the topographical image. ${ }^{21}$
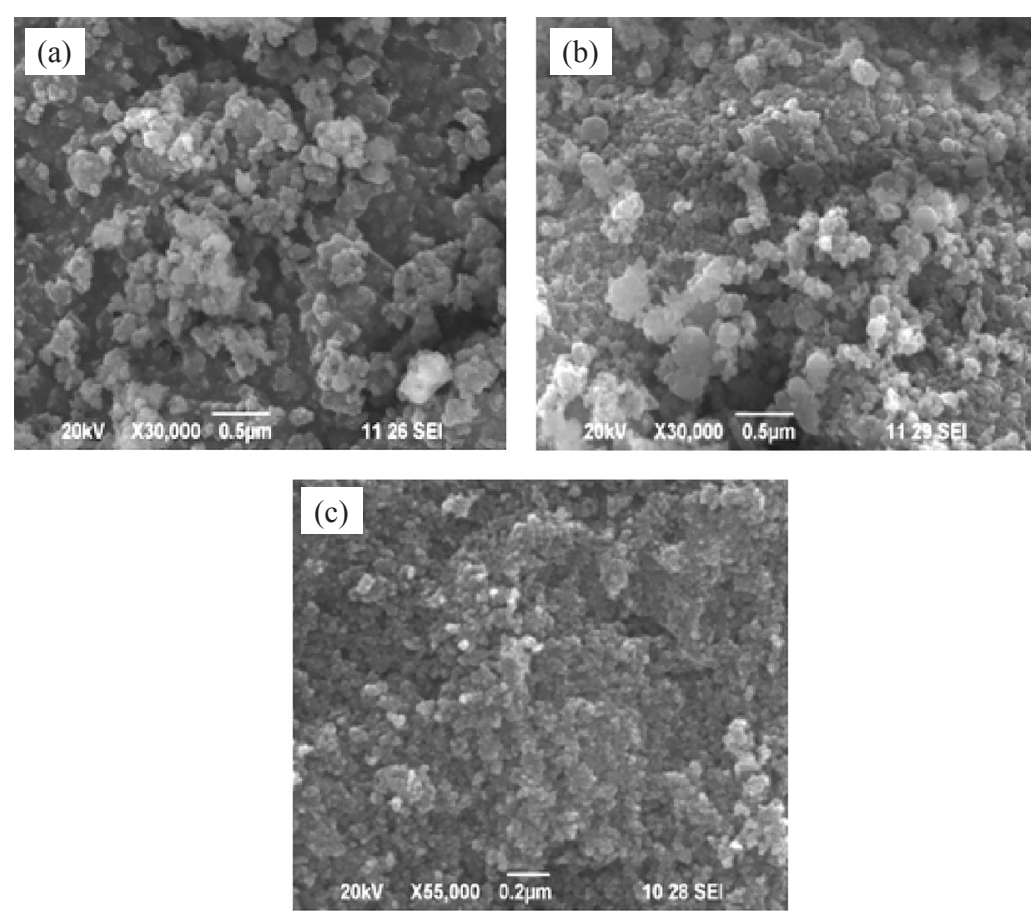

Figure 4: SEM images of (a) pure (b) $0.25 \mathrm{M}$ zinc, and (c) $0.50 \mathrm{M}$ zinc added $\mathrm{MgO}$ nanoparticles.

\subsection{Electrical Studies}

The flat surface of the cylindrical pellets was prepared using a hydraulic press (with 4 tons pressure) and the pellets were coated with a silver paste to obtain a good conductive surface layer. The pellet was placed between the electrodes of the experimental cell. The electrical conductivity, dielectric constant and dielectric loss for pure, $0.25 \mathrm{M}$ and $0.50 \mathrm{M}$ zinc added $\mathrm{MgO}$ nanoparticles were measured by the result obtained from impedance analyser at different temperatures in the frequency range of $1 \mathrm{~Hz}-100 \mathrm{kHz}$.

The bulk resistance $\left(\mathrm{R}_{\mathrm{b}}\right)$ of pure, $0.25 \mathrm{M}$ and $0.50 \mathrm{M}$ zinc added $\mathrm{MgO}$ nanoparticles were found out from the impedance plot. The electrical conductivity of pure, $0.25 \mathrm{M}$ and $0.50 \mathrm{M}$ zinc added $\mathrm{MgO}$ nanoparticles were calculated and it was 
found in the order of $10^{-8} \mathrm{mho} \mathrm{m}^{-1}$ at room temperature. Also, it was observed that the conductivity decreased with increase in the temperature and the dopant concentration.

In order to understand the conduction mechanism in these samples, the electrical conductivity was plotted against 1000/T shown in Figure 5. All the prepared samples showed the Arrhenius type behaviour and observed that there are two activation energies in the temperature range considered. ${ }^{22}$

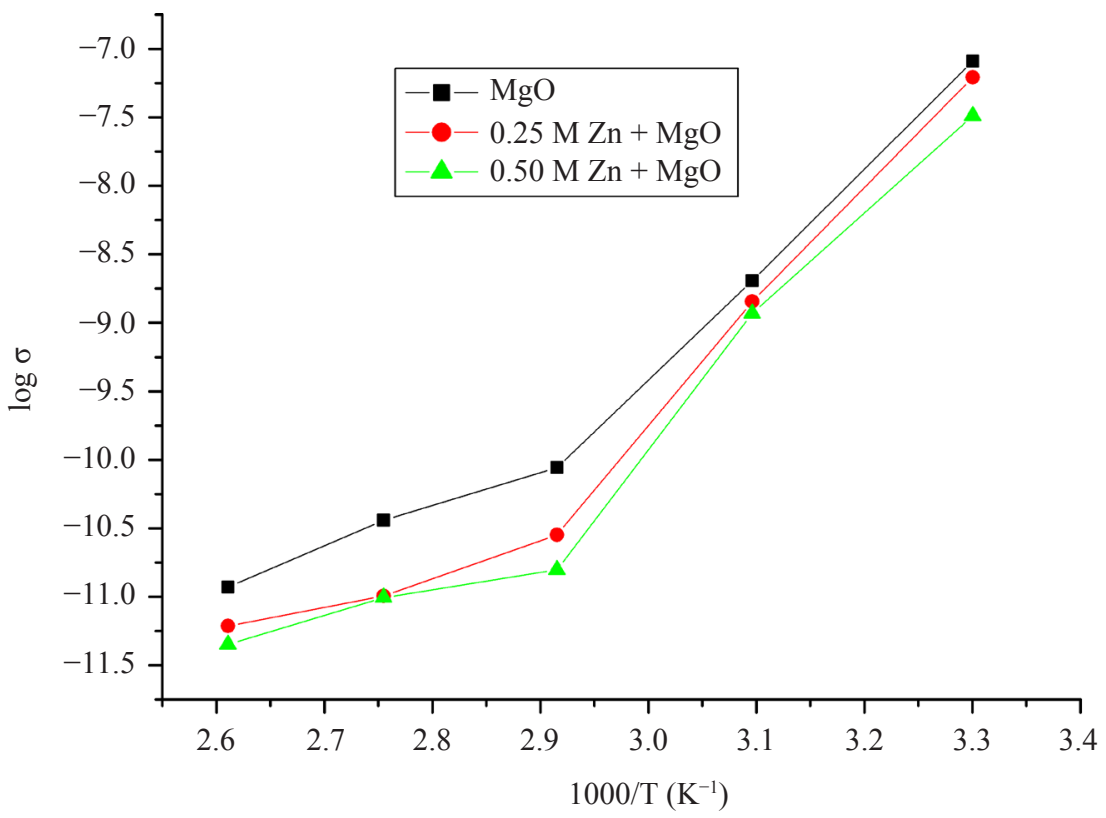

Figure 5: Variation of conductivity with temperature of pure and zinc added $\mathrm{MgO}$ nanoparticles.

These plots have a nature similar to intrinsic-to-extrinsic transition found in an electronic semiconductor. The presence of protons able to be exchanged and diffuse through interspaces makes these materials protonic conductors. ${ }^{23}$ The variation in electrical conductivity yields two straight lines of different slopes showing that there exist two types of conduction in the prepared pure and zinc added $\mathrm{MgO}$ nanoparticles. The one at low temperature is extrinsic and the other at high temperature is intrinsic. The activation energies in the extrinsic and intrinsic ranges were calculated for all the pure, $0.25 \mathrm{M}$ and $0.50 \mathrm{M}$ zinc added $\mathrm{MgO}$ nanoparticles are presented in Table 2 . The low activation energies in the intrinsic region show that the conductivity is predominantly due to the movement of defects produced by thermal activation. 
Table 2: Activation energy of pure and zinc added $\mathrm{MgO}$ nanoparticles.

\begin{tabular}{lcc}
\hline \multirow{2}{*}{ Sample } & \multicolumn{2}{c}{ Activation energy $(\mathrm{eV})$} \\
\cline { 2 - 3 } & Extrinsic & Intrinsic \\
\hline Pure $\mathrm{MgO}$ & 0.6649 & 0.2468 \\
$0.25 \mathrm{M}$ zinc added $\mathrm{MgO}$ & 0.7477 & 0.1888 \\
$0.50 \mathrm{M}$ zinc added $\mathrm{MgO}$ & 0.7400 & 0.1527 \\
\hline
\end{tabular}

The frequency dependence of dielectric constant and dielectric loss in the temperature range from $30^{\circ} \mathrm{C}$ to $110^{\circ} \mathrm{C}$ of the pure, $0.25 \mathrm{M}$ and $0.50 \mathrm{M}$ zinc added $\mathrm{MgO}$ nanoparticles are presented in Figures 6 and 7, respectively. It is observed that there is a variation of dielectric constant and loss with frequency at different temperatures for pure, $0.25 \mathrm{M}$ and $0.50 \mathrm{M}$ zinc added $\mathrm{MgO}$ nanoparticles over the entire measured range.

From Figures 6 and 7, it was found that the dielectric constant of pure and zinc added $\mathrm{MgO}$ nanoparticles gradually increased with increasing frequency for the entire temperature range. At the high frequency region, the dielectric constant is independent of temperature. But at the low frequency region, the dielectric constant of all the prepared samples increases when the temperature increases from $323 \mathrm{~K}$ to $343 \mathrm{~K}$ and decreases when the temperature increases from $363 \mathrm{~K}$ to $383 \mathrm{~K}$. The dielectric loss of pure and zinc added $\mathrm{MgO}$ nanoparticles is more independent of temperature up to $10 \mathrm{kHz}$ and above the frequency, it is more dependent. Further, it was also observed that the doping of zinc on $\mathrm{MgO}$ has decreased the dielectric constant at a given temperature. In the case of $0.25 \mathrm{M}$ and $0.50 \mathrm{M}$, zinc added $\mathrm{MgO}$ nanoparticles have low dielectric constant at entire frequencies. Hence, at all temperatures, the dielectric constant gradually increases up to the $10 \mathrm{kHz}$ and above $10 \mathrm{kHz}$, the dielectric constant increases rigorously. The increase in dielectric constant with increasing temperature can be attributed to space charge polarisation near the grain boundary interfaces which depends on the purity and perfection of the sample. ${ }^{24,25}$ The high dielectric constant in the higher frequency region of the sample can be assigned to the presence of interfacial, i.e., space charge polarisation mechanism and the low value of dielectric constant at lower frequencies may be due to the loss of significance of space charge polarisation gradually. Due to this effect, the dielectric constant attains a constant minimum value thereby leading the relaxation time for the electronic polarisation to be lesser than that of other types of polarisation. 


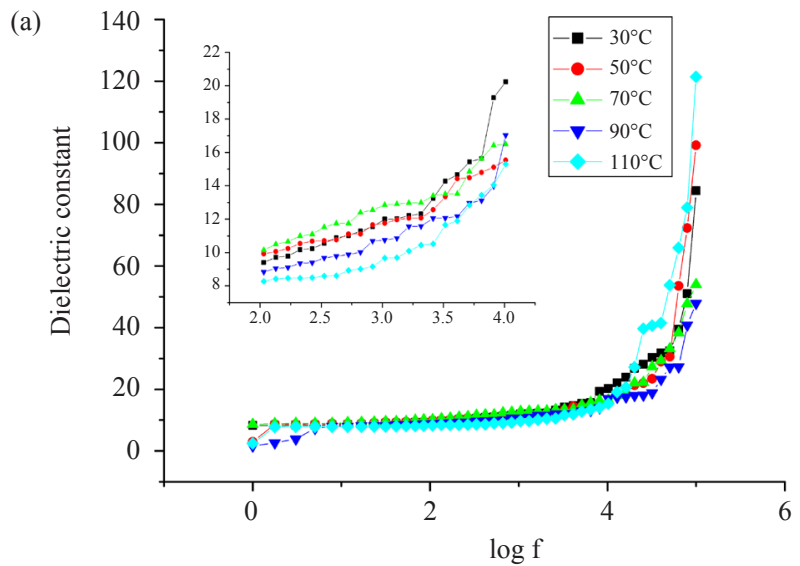

(b)
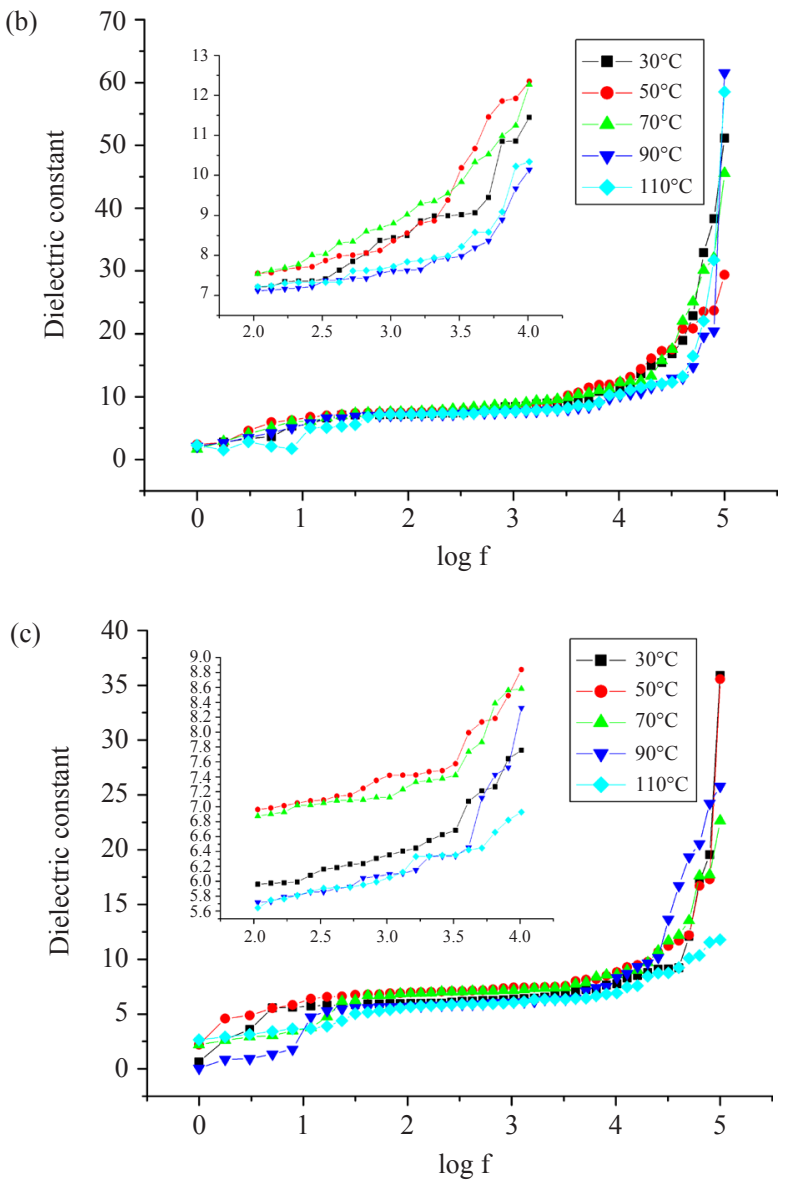

Figure 6: Frequency dependence of dielectric constant for (a) pure (b) $0.25 \mathrm{M}$ zinc, and (c) $0.50 \mathrm{M}$ zinc added $\mathrm{MgO}$ nanoparticles at different temperatures. 


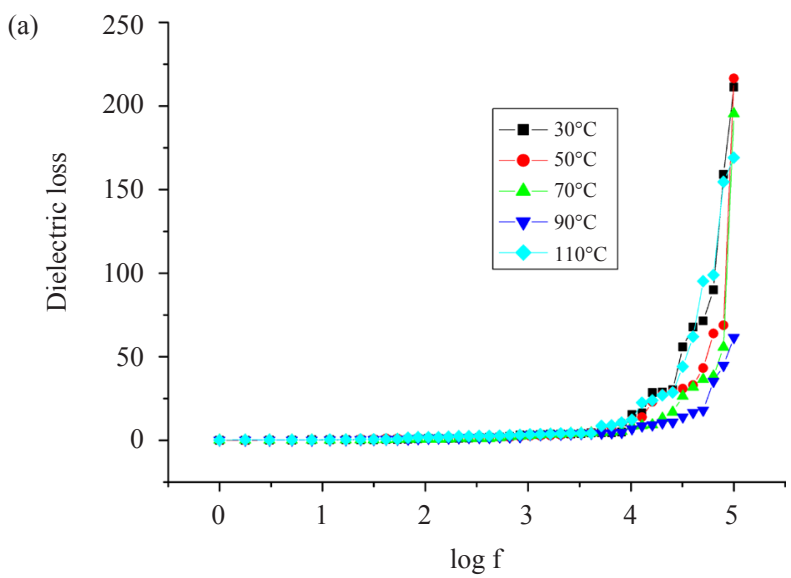

(b)

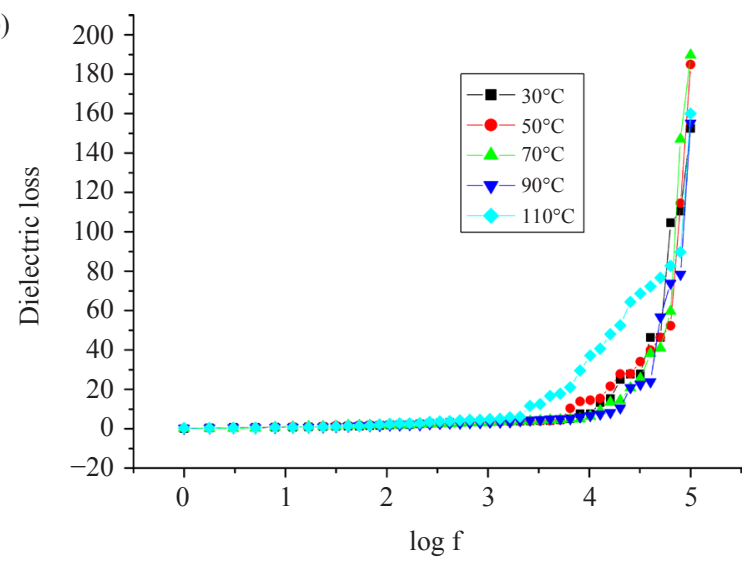

(c)

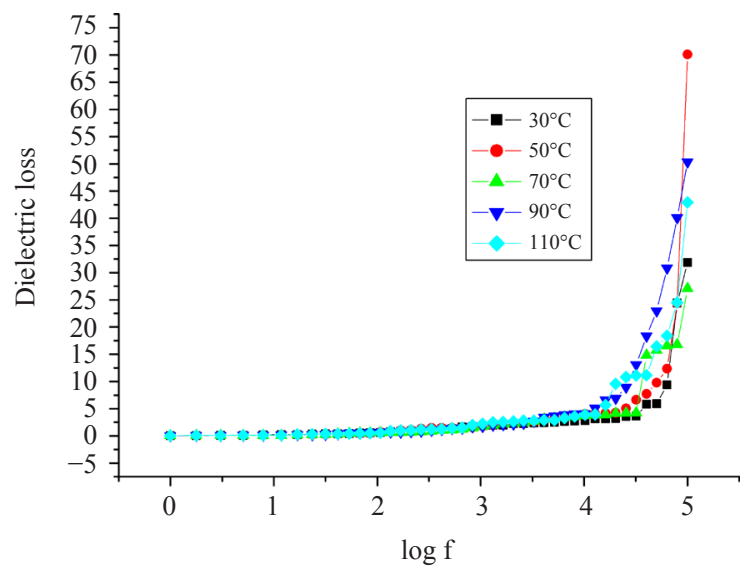

Figure 7: Frequency dependence of dielectric loss for (a) pure (b) $0.25 \mathrm{M}$ zinc, and (c) $0.50 \mathrm{M}$ zinc added $\mathrm{MgO}$ nanoparticles at different temperatures. 


\section{CONCLUSION}

Microwave assisted zinc added $\mathrm{MgO}$ nanoparticles were synthesised by the solvothermal method. The structural and electrical properties of the synthesised nanoparticles were studied with PXRD, EDS, SEM and impedance spectroscopy. The indexed PXRD data showed that $\mathrm{MgO}$ and zinc added $\mathrm{MgO}$ nanoparticles belong to the cubic structure. The increase in lattice volume and grain size of pure and zinc added $\mathrm{MgO}$ nanoparticles was observed with an increase in zinc molar concentration. The energy dispersive spectrum and SEM images of pure and zinc added $\mathrm{MgO}$ nanoparticles confirmed the presence of all elements and the formation of nanoclusters, respectively. The electrical conductivity of pure and zinc added $\mathrm{MgO}$ nanoparticles was observed and it decreases with increases in both temperature and impurity concentration. The low activation energy was found in the intrinsic region in the case of zinc added magnesium oxide nanoparticles. The dielectric constant and dielectric loss of pure and zinc added $\mathrm{MgO}$ nanoparticles increase with increasing frequency. Also, the dielectric constant and the dielectric loss of all the prepared samples are dependent of temperature up to $10 \mathrm{kHz}$ and above $10 \mathrm{kHz}$, they are more independent of temperature. The high dielectric constant of pure and zinc added $\mathrm{MgO}$ nanoparticles at higher frequency region is due to the presence of interfacial.

\section{REFERENCES}

1. Pearton, S. J. et al. (2003). Recent progress in processing and properties of ZnO. Superlatt. Microstr., 34(1-2), 3-32. https://doi.org/10.1016/S0749 $-6036(03) 00093-4$

2. Kilinc, N. et al. (2010). Structure and electrical properties of Mg-doped $\mathrm{ZnO}$ nanoparticles. Cryst. Res. Technol., 45(5), 529-538. https://doi.org/10.1002/ crat.200900662

3. Thierry, P. \& Daniel, L. (2000). Electrodeposition of semiconductors for optoelectronic devices: Results on zinc oxide. Electrochim. Acta, 45(20), 33453353. https://doi.org/10.1016/S0013-4686(00)00405-9

4. Ramanujam, K. \& Sundrarajan, M. (2014). Antibacterial effects of biosynthesized $\mathrm{MgO}$ nanoparticles using ethanolic fruit extract of Emblica officinalis. J. Photochem. Photobiol. B, 141, 296-300. https://doi.org/10.1016/j.jphotobiol .2014.09.011

5. Ramesan, M. T. et al. (2020). Structural, electrical, thermal and gas sensing properties of new conductive blend nanocomposites based on polypyrrole/ phenothiazine/silver doped zinc oxide. J. Vinyl Addit. Tech., 26(2), 187-195. https://doi.org/10.1002/vnl.21732 
6. Ramesan, M. T. et al. (2018). Effect of silver doped zinc oxide as nanofiller for the development of biopolymer nanocomposites from chitin and cashew gum. J. Polym. Environ., 26, 2983-2991. https://doi.org/10.1007/s10924-018-1187-6

7. Ramesan, M. T. et al. (2017). Temperature-dependent AC electrical conductivity, thermal stability and different DC conductivity modelling of novel poly(vinyl cinnamate)/zinc oxide nanocomposites. J. Therm. Anal. Calorim., 129, 135-145. https://doi.org/10.1007/s10973-017-6140-8

8. Kakhaki, Z. M. Youzbashi, A. \& Naderi, N. (2015). Optical properties of zinc oxide nanoparticles prepared by a one-step mechanochemical synthesis method. J. Phys. Sci., 26(2), 41-51.

9. Stankic, S. et al. (2016). Pure and multi metal oxide nanoparticles: Synthesis, antibacterial and cytotoxic properties. J. Nanobiotechnol., 14, 73-80. https://doi .org/10.1186/s12951-016-0225-6

10. Jayaprakash, J. et al. (2015). Synthesis and characterization of cluster of grapes like pure and Zinc-doped $\mathrm{CuO}$ nanoparticles by sol-gel method. Spectrochim. Acta A, 136(Part C), 1803-1806. https://doi.org/10.1016/j.saa.2014.10.087

11. Abdul Rahman, A. et al. (2013). Effect of nanorod zinc oxide on electrical and optical properties of starch-based polymer nanocomposites. J. Phys. Sci., 24(1), $17-28$.

12. Barick, K. C. et al. (2010). Porosity and photocatalytic studies of transition metal doped $\mathrm{ZnO}$ nanoclusters. Microp. Mesop. Mater., 134(1-3), 195-202. https://doi.org/10.1016/j.micromeso.2010.05.026

13. Manjula, G. N. et al. (2011). Structural, optical, photo catalytic and antibacterial activity of $\mathrm{ZnO}$ and $\mathrm{Co}$ doped $\mathrm{ZnO}$ nanoparticles. Mater. Lett., 65(12), 1797-1800. https://doi.org/10.1016/j.matlet.2011.03.079

14. Jayakumar, O. D. et al. (2006). Magnetism in Mn-doped $\mathrm{ZnO}$ nanoparticles prepared by a co-precipitation method. Nanotechnol., 17(5), 1278-1285. https://doi.org/10.1088/0957-4484/17/5/020

15. Srinivasa Rao, L. et al. (2018). Structural and optical properties of zinc magnesium oxide nanoparticles synthesized by chemical co-precipitation. Mater. Chem. Phys., 203(1), 133-140. https://doi.org/10.1016/j.matchemphys.2017.09.048

16. Anandan, K., Siva, D. \& Rajesh, K. (2018). Structural and optical properties of (ZnO/MgO) nanocomposites. Int. J. Eng. Sci. Res. Technol., 7(8), 493-499. https://doi.org/10.5281/zenodo.1401731

17. Kaviyarasu, K. et al. (2015). A comparative study on the morphological features of highly ordered $\mathrm{MgO}: \mathrm{AgO}$ nanocube arrays prepared via a hydrothermal method. RSC Adv., 5, 82421-82428. https://doi.org/10.1039/C5RA15132E

18. Syamala Bai, Ramesh Kumar, D. V. \& Padma Suvarna, R. (2017). Synthesis and characterization of zinc oxide nanoparticles by solution combustion method: DC conductivity studies. Ind. J. Adv. Chem. Sci., 5(3) 137-141. https://doi.org/ 10.22607/IJACS.2017.503004

19. Sumithraj Premkumar, P. \& Sahaya Shajan, X. (2010). X-ray and thermal studies on $\mathrm{Zn}_{\mathrm{x}} \mathrm{Mg}_{1-\mathrm{x}} \mathrm{SO}_{4} .7 \mathrm{H}_{2} \mathrm{O}$ crystals. E-J. Chem., 7(S1), S121-S126. https://doi.org/ $10.1155 / 2010 / 518510$ 
20. Sumithraj Premkumar, P., Dawn Dharma Roy, S. \& Sahaya Shajan, X. (2014). Growth, structural and optical studies on pure and doped magnesium sulphate heptahydrate single crystals. Chem. Sci. Trans., 3(1), 359-367. https://doi.org/10 $.7598 /$ cst2014.721

21. Stefanos, M. Roger M. P. \& Nguyen T. K. T. (2018). Characterization techniques for nanoparticles: Comparison and complementarity upon studying nanoparticle properties. Nanosc., 10, 12871-12934. https://doi.org/10.1039/C8NR02278J

22. Sumithraj Premkumar, P. (2019). Preparation and electrical studies on pure and oxygen plasma treated polyvinyl alcohol films. J. Mater. Res. Technol., 8(2), 2232-2237. https://doi.org/10.1016/j.jmrt.2018.12.023

23. Gowri, B. \& Sahaya Shajan, X. (2006). Electrical conductivity studies on pure and copper added strontium tartrate trihydrate crystals. Mater. Lett., 60(11), 13381340. https://doi.org/10.1016/j.matlet.2004.08.050

24. Mazumder, R. et al. (2006). Particle size dependence of magnetization and phase transition near $\mathrm{T}_{\mathrm{N}}$ in multiferroic $\mathrm{BiFeO}_{3}$. J. Appl. Phys., 100(3), 033908. https://doi.org/10.1063/1.2229667

25. Joshi, S. J. et al. (2010). Characterization of gel grown iron-manganese-cobalt ternary levo-tartrate crystals. Cryst. Res. Technol., 45(3), 303-310. https://doi.org/ 10.1002/crat.200900152 